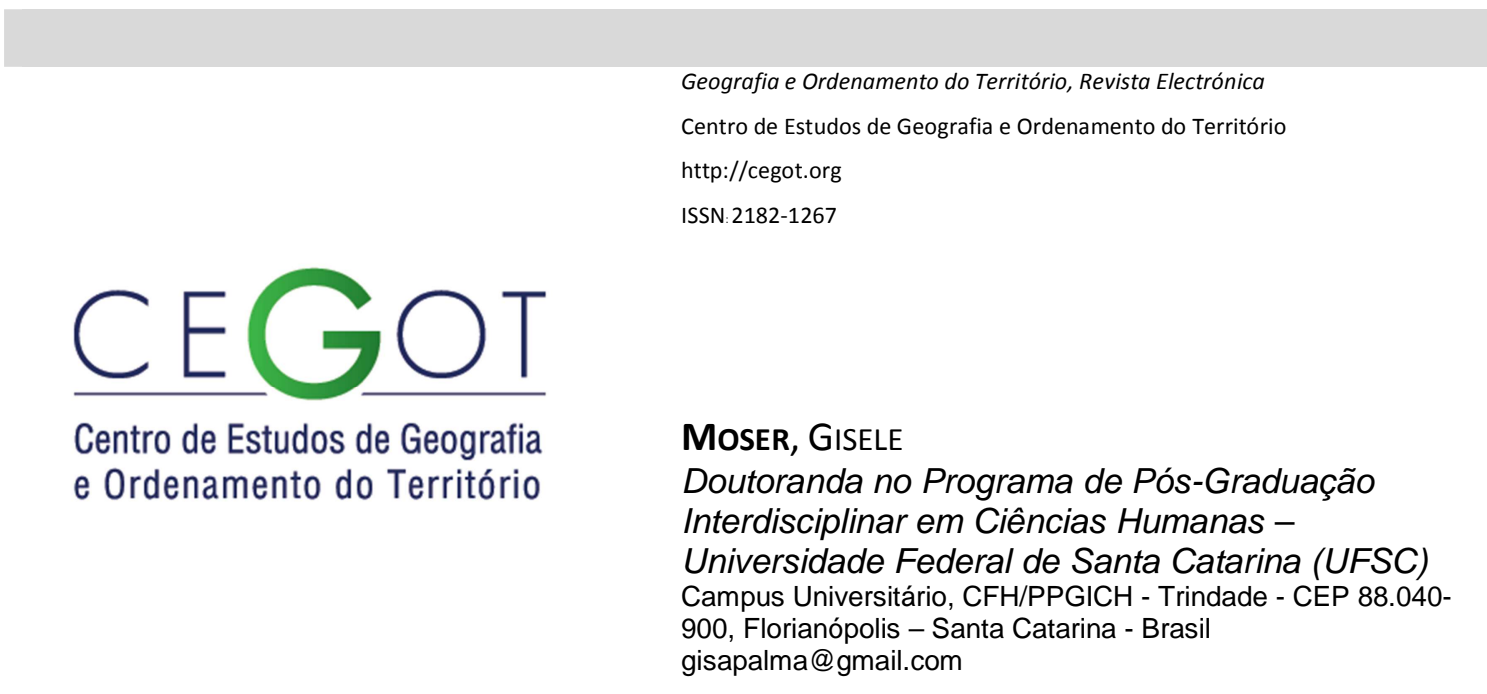

\title{
Transformações do espaço urbano costeiro: patrimonialização do meio ambiente na cidade de Florianópolis/Santa Catarina - Brasil
}

Transformations of the coastal urban space: the patrimonialization of the environment in the city of Florianópolis/Santa Catarina - Brazil

Referência: Moser, Gisele (2015). Transformações do espaço urbano costeiro: patrimonialização do meio ambiente na cidade de Florianópolis/Santa Catarina - Brasil. Revista de Geografia e Ordenamento do Território (GOT), n.o 8 (dezembro). Centro de Estudos de Geografia e Ordenamento do Território, p. 133-144, dx.doi.org/10.17127/got/2015.8.007

\section{RESUMO}

Neste trabalho problematizo a cidade de Florianópolis sob os aspectos do desenvolvimento da maricultura, projetando-a como grande produtora nacional de ostras e mariscos, e da praia, que outrora servia para receber os despejos da cidade e foi elevada à condição de espaço de lazer e veraneio. Estes elementos - mar e praia - passaram por novas configurações, a partir da apropriação e ressignificação de antigos usos dos recursos naturais, de tal modo que ocorrem transformações na perspectiva social e ambiental. A patrimonialização do meio ambiente insere-se numa perspectiva turística como um processo que se apresenta indissociável das novas estratégias de apropriação das imagens da cidade e de marketing da cidade, tornado a cidade uma imagem a ser consumida com um modelo idealizado de espaços urbanos padronizados.

Palavras-chave: cidade; história urbana; meio ambiente; patrimonialização; Florianópolis.

\section{ABSTRACT}

In this paper we discuss the city of Florianópolis in aspects of development of mariculture, projecting it as a large national producer of oysters and shellfish, and the beach, which once 
served to receive the city evictions and was raised to become a leisure area and a site for summer vacations. These elements - sea and beach - experienced new settings, from the appropriation and reinterpretation of old uses of natural resources, in a way that they changed the social and environmental perspective. Environmental patrimonialization is part of a touristic perspective as a process that appears inseparable from the new strategies of appropriation of images of the city and city marketing, turining the city into an image to be consumed with an idealized model of standardized urban spaces.

Keywords: city; urban history; environment; patrimonialization; Florianópolis.

\section{Expansão territorial numa ilha}

A cidade de Florianópolis, capital do estado de Santa Catarina, localizada no litoral do Sul do Brasil, hoje com cerca de 450 mil habitantes, é composta por uma parte territorial no continente, com treze quilômetros quadrados, e outra parte insular, numa área de 420 quilómetros quadrados. Deste território insular, nove quilómetros quadrados da área total foram incorporados através de aterros feitos desde o final do século XIX, utilizando-se principalmente o método de aterro hidráulico, conforme indicam os Estudos de Impacto Ambiental/Relatório de Impacto no Meio Ambiente (EIA/RIMA), documentos obrigatórios na construção de obras urbanas. ${ }^{1} \mathrm{O}$ aterro hidráulico utiliza a água como um aspirador de pó para levar a areia do fundo do mar para a superfície, diferente do aterro mecânico, como o realizado na Avenida Beira Mar Norte, em que ocorre o transporte rodoviário de material (PROCHNOW, 2009, p.9). Estes aterros fazem parte do chamado processo de "higienização" ocorrido no Brasil, como parte das políticas urbanísticas então vigentes, e que permitiram a ampliação territorial com a construção de bulevares e novas vias de circulação para automóveis, havendo a expulsão dos pobres que habitavam nestas áreas e a eliminação dos cortiços $^{2}$ das áreas centrais ou de interesse.

\footnotetext{
${ }^{1}$ Os documentos referentes a cada obra podem ser consultados no Instituto de Planejamento Urbano de Florianópolis (IPUF) e na Fundação do Meio Ambiente de Santa Catarina (FATMA).

${ }^{2}$ Os cortiços abrigavam a população mais pobre da cidade, em geral habitados por pescadores, marinheiros, lavadeiras, soldados, escravos libertos e prostitutas. Conforme aponta Flávio Villaça, o cortiço é um tipo de área residencial central das camadas de baixa renda muito comum nas cidades brasileiras no final do século XIX (VILLAÇA, 1998, p.229). “O cortiço é a 'solução' de mercado, é uma moradia alugada, é um produto da iniciativa privada. Em seus diversos tipos, foi a primeira forma física de habitação oferecida ao 'homem livre' brasileiro da mesma forma que o aluguel foi a primeira forma econômica" (VILLAÇA apud SUGAI, 1994, p.17).
} 
Em Florianópolis, a organização do centro urbano da cidade deu-se ligada à existência de fontes de água e à orla marítima, com a fixação dos moradores em torno do largo da Igreja Matriz, acompanhando os caminhos que levavam às fontes até ao século XVIII. No século $\mathrm{XIX}$, os caminhos passaram a seguir o mar em direção ao porto. As casas eram construídas de costas para o mar e a praia era lugar de despejo. Narra o historiador Oswaldo Cabral que, no século XIX, após o toque de recolher dado às nove horas da noite, os escravos saíam às ruas com uma espécie de balde na cabeça levando os dejetos e excrementos reunidos durante o dia para serem despejados no mar (CABRAL, 1971, p.215). À medida que a cidade crescia, aumentava também o hábito de jogar lixo e entulho nas praias e nos mangues, e então começavam a surgir os primeiros projetos para aterros na ilha (CECCA, 1996, p.56).

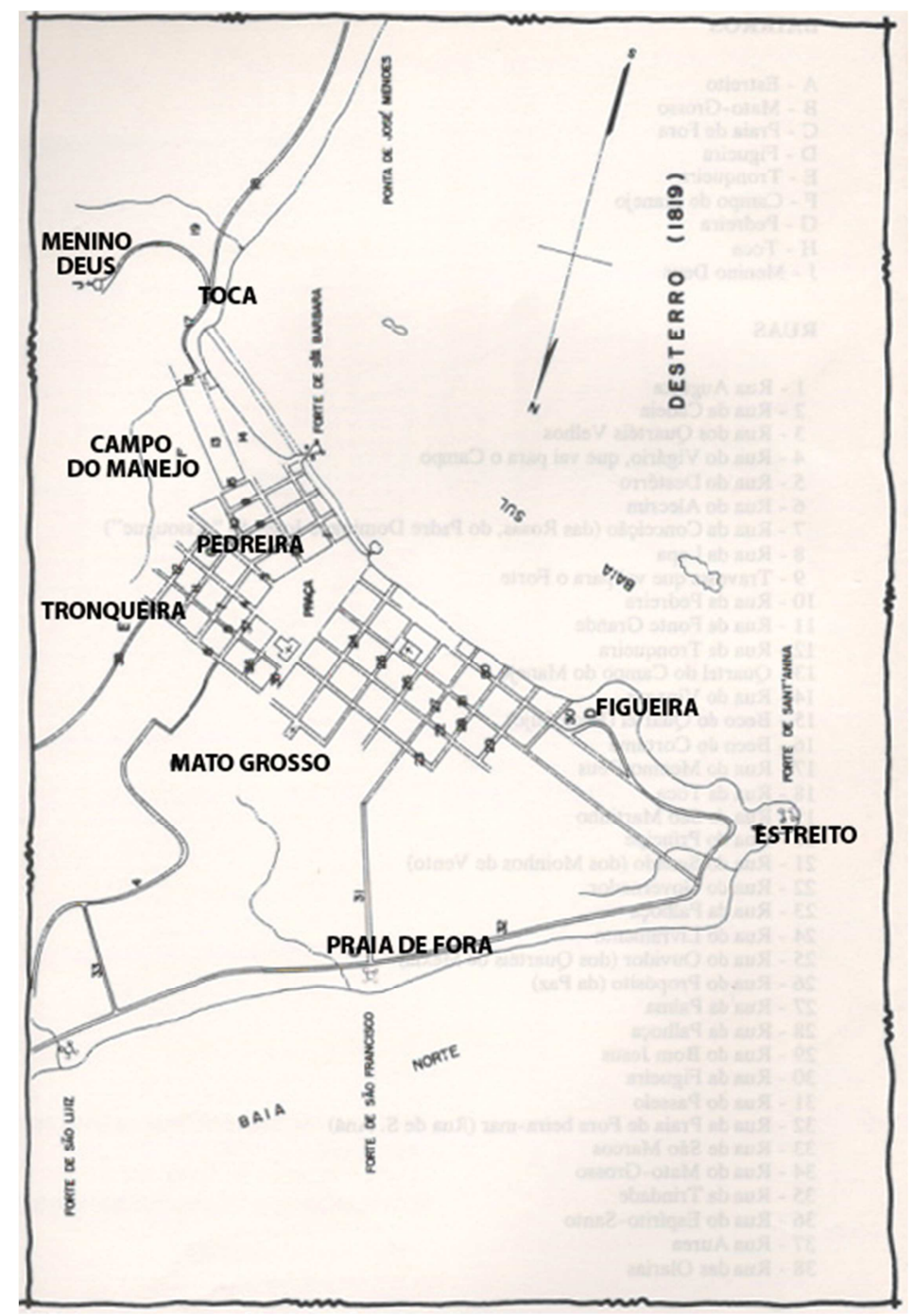

Figura 1 - Mapa de Desterro em 1819 (nomes dos bairros aplicados pela autora).

Fonte: CABRAL apud VEIGA, 1993, p.91. 
No Jornal do Comércio, veiculado na cidade de Florianópolis (que então se chamava Nossa Senhora do Desterro) em 18 de janeiro de 1884, aparece um dos primeiros registros com a proposta para se aterrar os terrenos alagadiços da praia do Menino Deus. Conforme o relatório ${ }^{3}$ daquele ano elaborado pelo presidente da província de Santa Catarina, Francisco José da Rocha, o intuito do aterro era o de aproveitar a área conquistada ao mar para logradouro público e para edificações, e ao mesmo tempo remover os "esterquilínios" que ali se formavam, além de impedir a continuidade do depósito de lixo no local. Logo, em 1884, começaram os trabalhos para a realização do primeiro aterro da cidade, na Praia da Boa Vista, que se estendia do forte Santa Bárbara até o início da ladeira do Menino Deus, na subida do Hospital de Caridade. Nos anos seguintes, outros aterros foram feitos na área central, além da canalização de diversos rios, o que gerou problemas de escoamento das águas de morros próximos, como no caso do Rio da Bulha ${ }^{4}$ (sob a atual Avenida Hercílio Luz). Outro problema ocorreu com a transferência do cemitério municipal, que antes ocupava os arredores da igreja, para o topo do morro contaminando as águas da principal vertente que abastecia a cidade.

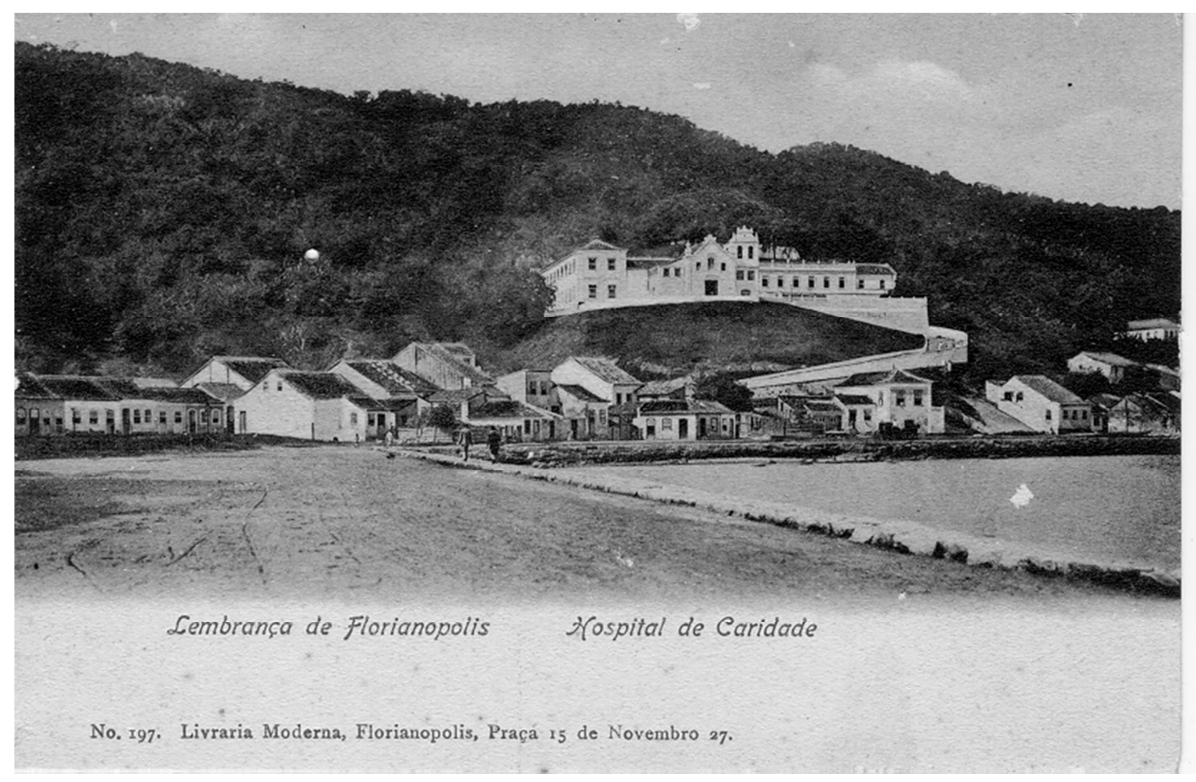

Figura 2 - Aterro da Praia da Boa Vista, por volta de 1900, no alto o Hospital de Caridade. Fonte: Banco de Imagens do Arquivo do Instituto Histórico e Geográfico de Santa Catarina.

\footnotetext{
${ }^{3}$ Relatório apresentado à Assembleia Legislativa da Província de Santa Catarina pelo presidente Dr. Francisco José da Rocha. Desterro: 20 maio de 1888. Disponível para consulta no Arquivo Público do Estado de Santa Catarina, Centro, Florianópolis/Santa Catarina.

${ }^{4}$ O Rio da Bulha era o maior e mais caudaloso, tendo sua nascente no Morro da Boa Vista.
} 
Dentre tantos aterros, podemos citar alguns que geraram grande impacto nas áreas em que foram instalados: na década de 1940 foi realizado um aterro no Largo 13 de Maio, imediações do Hospital de Caridade; nos anos de 1960 foi iniciado o aterro da baía Norte, correspondente a atual avenida Beira-Mar Norte; na década de 1970 foi feito um aterro para a cabeceira da ponte Colombo Salles, que liga a ilha ao continente, e os 440 mil metros quadrados do aterro da baía Sul, com projeto de urbanização e paisagismo elaborados por Burle Marx, nunca implantados, contemplando áreas de lazer e esportes; nos anos 2000 foram realizado os aterros da Via Expressa Sul (ligação do Centro até o aeroporto) e da Beira-Mar Continental (planejado já na década de 1950), na área continental da cidade.

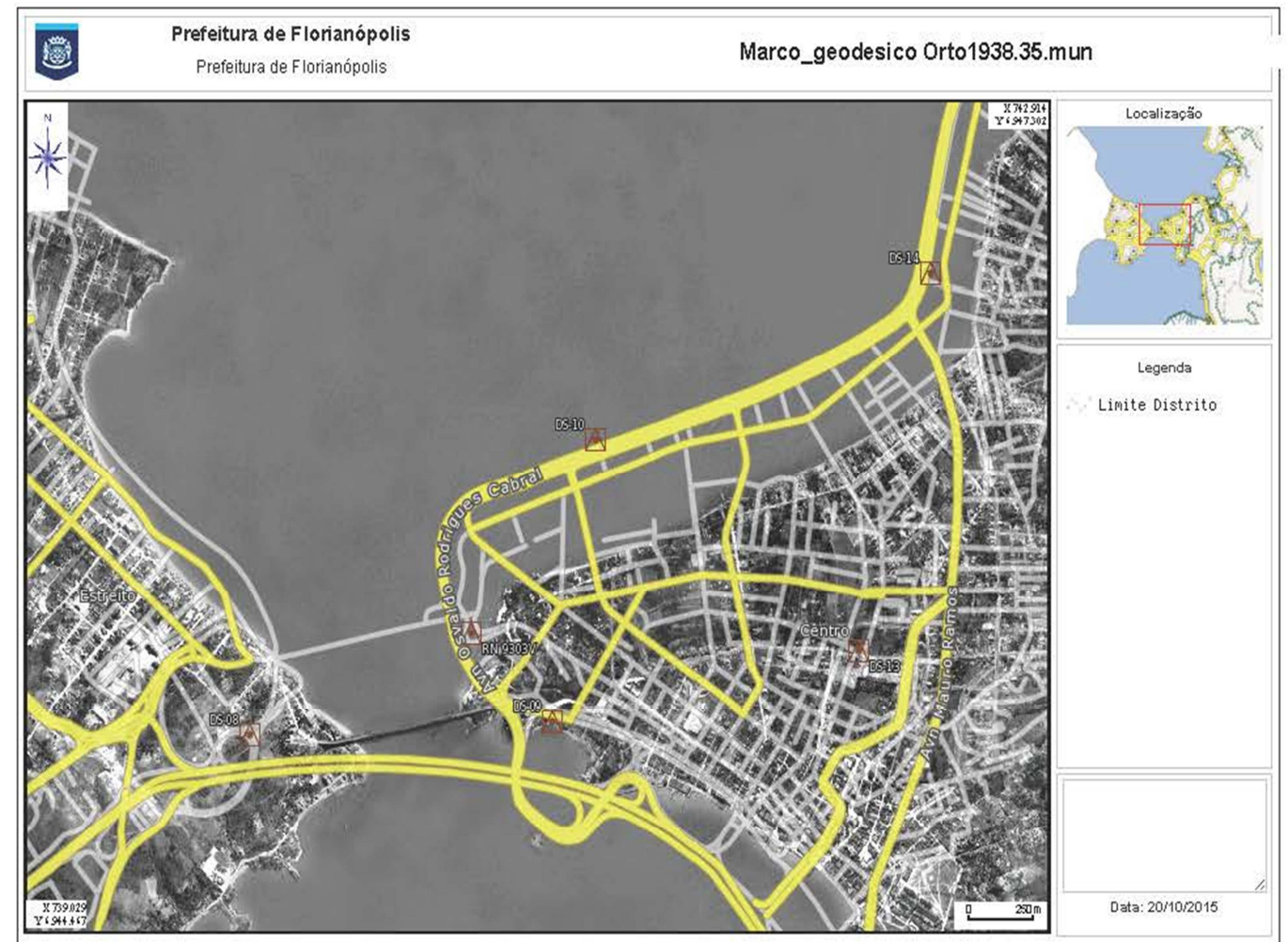

Figura 3 - Mapa de Florianópolis de 1938 com marcação atual dos avanços sobre o mar. Fonte: Geoprocessamento Corporativo Florianópolis, disponível em <http://geo.pmf.sc.gov.br/>.

\subsection{Meio ambiente e turismo}

Da sequência de aterros na área central da cidade, a utilização do mar como estação balneária deu-se em lugares mais afastados, sendo a Praia de Fora, na baía Norte, considerada o local ideal para o banho de mar. Já nas duas últimas décadas do século XIX, os habitantes com maior poder aquisitivo construíram na Praia de Fora seus sobrados com a 
frente voltada para o mar. Eram suas residências de fim de semana, pois a moradia em geral localizava-se no Centro com seus comércios na mesma casa. Virgílio Várzea afirmava que "poucos lugares no globo possuirão praias tão bonitas e de um desenho mais interessante e caprichoso como as da costa catarinense, tanto na llha como no continente" (VÁRZEA, 1985, p.113). Considerava a Praia de Fora como "a principal de Florianópolis" e como "a primeira estação balnear da capital, cuja população para aí acode, em parte, na época própria, habitando as casas da beira-mar" (VÁRZEA, 1985, p.113-114).

O que antes se referia como "estação de águas" ou "estação balnear" deu lugar ao termo "turismo" que começou a ser empregado em Florianópolis no final da década de 1940 (FERREIRA, 1998, p.100-102). A partir da década de 1950, o setor de turismo passa a concentrar boa parte dos investimentos e na década de 1970 consolida-se como um importante meio econômico da cidade. Os financiamentos facilitados através do Banco Nacional de Habitação (BNH) impulsionaram a expansão imobiliária e aos poucos foram criados pequenos núcleos residenciais em áreas destinadas aos turistas. A tabela abaixo (Figura 4) deixa claro o grande crescimento populacional, especialmente da década de 1980 para 1990, que obteve um incremento de 67 mil habitantes. Da mesma forma, de 2000 a 2008, contabilizou-se um crescimento de $53 \%$ no número anual de turistas em Florianópolis, conforme dados divulgados pela Santur. ${ }^{5}$ O que vale ser destacado é que ao mesmo tempo em que se registrou o aumentou do número de turistas também houve um aumento no número de moradores. Ou seja, muitos que chegaram até à cidade apenas como visitantes optaram pelo local para fixar residência, constatado pelo aumento significativo no número de habitantes em Florianópolis, chegando a 400 mil habitantes no ano de 2007, crescimento superior ao do Estado e do país. ${ }^{6}$ Diferente do discurso propagado na imprensa local que indica os "nativos" como a maioria, o Censo Demográfico de 2010, realizado pelo Instituto Brasileiro de Geografia e Estatística (IBGE), apresentou que 51,71\% dos moradores de Florianópolis são nascidos em outras cidades. ${ }^{7}$ Ao chegar no século XXI, a capital catarinense

\footnotetext{
${ }^{5}$ Dados da Santur apud Projeto Sinais Vitais Florianópolis. Instituto Comunitário Grande Florianópolis, 2008. Disponível em: <http://www.icomfloripa.org.br/sinais_vitais_08>. Acesso em: 15 jan. 2010.

${ }^{6}$ Dados do Instituto Brasileiro de Geografia e Estatística (IBGE). In: BIONDI, Antonio. Crescimento e turismo desordenados ameaçam encantos de Floripa. UOL Notícias. 25 jan. 2008.

${ }^{7}$ Dados do Instituto Brasileiro de Geografia e Estatística (IBGE). Disponível em: <www.ibge.gov.br/>.
} 
atinge a marca atual de mais de um milhão de habitantes no conglomerado que compõe a região metropolitana, chamada de Grande Florianópolis. ${ }^{8}$

\begin{tabular}{|c|c|}
\hline Ano & População Florianópolis \\
\hline 1960 & 97.827 \\
\hline 1970 & 138.337 \\
\hline 1980 & 187.871 \\
\hline 1991 & 254.941 \\
\hline 2000 & 342.315 \\
\hline
\end{tabular}

Figura 4 - Censo Demográfico IBGE 1960, 1970, 1980, 1991 e 2000. Coleção digital.

Este incremento populacional também se deve aos investimentos em propagandas realizados pelo governo do Estado e pela mídia que noticia constantemente Florianópolis associando aos seus atrativos naturais. Em pesquisa empírica realizada no cenário nacional e internacional percebemos que Florianópolis é citada como "a capital com melhor qualidade de vida" ${ }^{9}$ e Santa Catarina como "melhor destino turístico" ${ }^{10}$, sendo propagandeada como um destino turístico internacional comparadas a Ibiza (Espanha) e Saint-Tropez (França) ${ }^{11}$. Como resultado, todos os meses a capital recebe cerca de mil novos moradores que migram

\footnotetext{
${ }^{8}$ Dados do IBGE do Censo Demográfico 2010 indicam a Grande Florianópolis com 1.012.233 habitantes. De acordo com a Associação dos Municípios da Grande Florianópolis, este conglomerado é composto por 22 municípios: Águas Mornas, Alfredo Wagner, Angelina, Anitápolis, Antônio Carlos, Biguaçu, Canelinha, Florianópolis, Garopaba, Governador Celso Ramos, Leoberto Leal, Major Gercino, Nova Trento, Palhoça, Paulo Lopes, Rancho Queimado, Santo Amaro da Imperatriz, São Bonifácio, São João Batista, São José, São Pedro de Alcântara e Tijucas.

${ }^{9} \mathrm{Em}$ 2000, Florianópolis foi eleita como a capital com melhor qualidade de vida do país pelo Atlas de Desenvolvimento Humano, do Programa das Nações Unidas para o Desenvolvimento (PNUD), tendo como base 0 índice de Desenvolvimento Humano (IDHM). Mais dados disponíveis em: <http://www.santacatarinabrasil.com.br/pt/qualidade-de-vida/>. Acesso em 23 out. 2015.

${ }^{10}$ Santa Catarina foi escolhido como o estado preferencial na categoria "Destino Turístico Nacional" pela revista especializada Brasil Travel News desde 2007 e apontado como "O melhor destino turístico do país" pela revista Viagem e Turismo/Editora Abril em 2007. Em 2012 recebeu novamente o título pela sexta vez consecutiva. Dados divulgados no site da Santa Catarina Turismo (Santur), empresa de economia mista vinculada à Secretaria de Estado da Cultura, Turismo e Esporte. Disponível em: <www.santur.sc.gov.br>. Acesso em: 11 maio 2010.

${ }^{11}$ Em 2009, o jornal italiano Corriere della Sera publicou uma matéria destacando a cidade de Florianópolis, expressando ser "surpreendente" o fato de uma cidade brasileira ter qualidade de vida alta, baixa criminalidade e fisionomias semelhantes aos europeus. A matéria fez referência à área de Jurerê como uma nova Saint-Tropez ou Ibiza. GIOVAGNINI, Maria Laura. Le città del futuro: Florianópolis. Corriere della Sera, 15 out. 2009. Roma, Itália, 15 out. 2009. Disponível em: <www.corriere.it/cronache/09_ottobre_15/iodonnacitta_410509d8-b993-11de-88c-00144f02aabc.shtml>. Acesso em: 19 out. 2009.
} 
por uma oportunidade de trabalho ou em busca da tão propagada qualidade de vida. ${ }^{12} \mathrm{O}$ que ocorre é que pelo menos $20 \%$ destes acabam constituindo os "bolsões de pobreza". ${ }^{13}$ Conforme dados da prefeitura de Florianópolis, no ano de 2001 foram identificados mais de 50 "bolsões de pobreza", correspondendo a $14,7 \%$ da população do município, compondo as chamadas "áreas de interesse social". ${ }^{14}$ Esse discurso entre o real da cidade e o propagado parece andar em descompasso diante das imagens que circulam reforçando apenas as "belezas naturais", ou seja, as praias, o mar e a vegetação presentes na ilha, invibilizando os problemas sociais existentes.

\subsection{Meio ambiente e patrimonialização}

Diante do cenário apresentado, a patrimonialização do meio ambiente insere-se numa perspectiva turística como um processo que se apresenta indissociável das novas estratégias de apropriação e de marketing, onde a cultura, e da mesma forma o meio ambiente, passam a ser uma imagem a ser consumida com um modelo idealizado de espaços urbanos padronizados, ocorrendo uma patrimonialização através das imagens produzidas da cidade (JEUDY, 2005, p.69). Pensando de acordo com o que propõe Andreas Huyssen, "a imagem da cidade propriamente dita torna-se central para seu sucesso em um mundo globalmente competitivo" (HUYSSEN, 2000, p.100). O city marketing ${ }^{15}$ passa a ser utilizado como um

\footnotetext{
${ }^{12}$ Projeção feita pela Secretaria Municipal de Urbanismo e Serviços Públicos (SUSP) e Centrais Elétricas de Santa Catarina (Celesc) com base nas ligações de energia elétrica realizadas mensalmente. In: REBEQUI, Aline. Ilha, o paraíso dos migrantes. Jornal Notícias do Dia. Florianópolis, 10 out. 2008.

13 “Bolsões de pobreza"é um termo utilizado pelos órgãos governamentais para referir-se aos aglomerados de famílias de baixa renda em áreas urbanas periféricas.

${ }^{14}$ Conforme descrito no documento "Programa Habitar Brasil" da Prefeitura Municipal de Florianópolis, as Áreas de Interesse Social são caracterizadas "pela forma de ocupação desordenada, irregular ou clandestina (...) situadas nas encostas dos morros da área insular, em terrenos com declividade menos acentuados em fundos de vales, especificamente na área do continente, havendo, ainda, comunidades situadas em áreas de mangues e dunas". Documendo disponível em: <http://www.pmf.sc.gov.br/arquivos/arquivos/pdf/07_01_2010_17.23.04.a575e7df24caedc9518a207cbae6ae b1.pdf>. p.12. Acesso em 23 out. 2015.

${ }^{15}$ O termo city marketing é empregado no sentido proposto por Fernanda Sánchez: "Se ler a cidade significa ter uma representação de cidade, construir uma imagem de cidade significa também compreender e interpretar e, sobretudo, sintetizar, dada a complexidade do fenômeno observado. Porém, "leituras", no plural, implicam que a cidade pode ser representada, ou melhor, imaginada, a partir de diversos olhares. Não há uma única leitura possível. (...) As imagens-síntese oficiais, aquelas que se impõem como dominantes em cada cidade onde opera um projeto de modernização urbana definido e explicitado, não deixam margem para dúvidas ou interpretações diversas sobre a informação que veiculam; não oferecem alternativas à sua
} 
instrumento das políticas públicas, no qual a representação do espaço passa a mostrar uma imagem ideal da cidade, transformando-a em mercadoria e atuando diretamente nos processos de intervenção para a renovação urbana (SANCHÉZ, 2001, p.34). Em Florianópolis, o city marketing tem se desenvolvido no intuito de atrair novos moradores com maior poder aquisitivo e investidores para as áreas de potencial turístico.

O termo "revitalização", vinculado a vários projetos urbanos apresentados pelo poder público ou em parcerias público-privadas, conforme aponta Neil Smith, mascara os objetivos da mudança urbana, sendo que "a linguagem da 'regeneração' substitui deliberadamente a linguagem simples e honesta da gentrificação ${ }^{16 \prime \prime}$ (SMITH, 2006, p.83). Pode-se dizer que existe aí uma tensão entre o meio ambiente e o desenvolvimento do turismo, permeados pelas memórias dos moradores e pelas expectativas dos investidores. A imagem da cidade voltada para o lazer e esvaziada das disputas torna invisível as tensões do cotidiano que hoje afetam a malha urbana fragmentada.

Da mesma forma, novos usos do mar vem sendo associados pautados por intencionalidades turísticas e comerciais, como o cultivo de ostras na costa catarinense. O desenvolvimento da maricultura na atualidade projeta a cidade como grande produtora nacional de ostras e mexilhões, representando $80 \%$ no mercado nacional, com uma capacidade de produção de 3,2 mil toneladas por ano. ${ }^{17} \mathrm{~A}$ maricultura trata-se do cultivo de organismos marinhos, atividade que vem crescendo devido à aplicação de novas técnicas e apresentando-se como uma fonte de renda alternativa à pesca artesanal - que se encontra em declínio frente à pesca industrial. Em Santa Catarina, a principal espécie de ostra cultivada não é nativa da região e sim de origem japonesa, ou do Pacífico (Crassostrea gigas), introduzida a partir de estudos feitos no final da década de 1980 pela Secretaria de Agricultura do Estado, através da Empresa de Pesquisa Agropecuária e Extensão Rural de Santa Catarina (EPAGRI), e pelo Laboratório de Moluscos Marinhos (LMM), da Universidade Federal de Santa Catarina

decodificação. Organizam, a seu modo, a cidade, tornando-a simbolicamente eficiente, uma espécie de publicidade que concretiza o modo de reconhecê-la e avaliá-la." (SÁNCHEZ, 2001, p.34).

${ }^{16}$ O termo gentrification foi utilizado pela primeira vez por Ruth Glass no início década de 1960, em Londres, compreendendo a transformação da composição social dos residentes (substituição das classes populares por classes médias assalariadas) e um processo de investimento, reabilitação e apropriação das áreas (BIDOUZACHARIASEN, 2006, p.22).

17 Dados disponíveis no site da Prefeitura de Florianópolis: <http://www.pmf.sc.gov.br/sites/fenaostra/index.php?pagina=home\&menu=0>. Acesso em 8 jun. 2015. 
(UFSC). Com o crescimento da cidade concomitante à produção da maricultura, um dos fatores que preocupa e que interfere na qualidade dos moluscos é a poluição, podendo afetar o cultivo e a saúde do consumidor, visto que muitas habitações não possuem canalizações corretas de seus esgotos e ainda despejando-os no mar (BECKER, 2008). Assim, a preservação do meio ambiente está na pauta das discussões dos órgãos envolvidos no desenvolvimento do cultivo na capital catarinense. Entre os riscos de poluição, a biológica ${ }^{18}$ é a que requer maior atenção, sendo as principais fontes de contaminação a partir de efluentes domésticos e dejetos agrícolas lançados sem tratamentos (WOLFF, 2007, p.166).

Em busca de uma efetividade da atividade de maricultura e de ampliação do mercado para os produtores foi criada a FENAOSTRA (Festa Nacional da Ostra e da Cultura Açoriana), realizada anualmente, com início em 1999 sob a organização do Instituto de Geração de Oportunidades de Florianópolis (IGEOF). Na página da prefeitura na internet diz: “O festival é um verdadeiro resgate da gastronomia e da cultura açoriana da Ilha de Santa Catarina" ${ }^{19}$ A afirmação torna-se contraditória diante da presença do cultivo de uma ostra que não é nativa da região e da produção recente, iniciada somente após o declínio da pesca. Tornase necessário problematizar esta naturalização de "resgate" e "cultura açoriana", cabendo investigar com maior detalhamento esta questão. Hoje, as comunidades produtoras de ostras em Florianópolis concentram-se no Sul da ilha, sendo a maior no Ribeirão da Ilha, seguida pelas do Norte, em Santo Antônio de Lisboa, Cacupé, Sambaqui e Praia do Forte. (SANTA CATARINA, 2013)

A seleção de um bem cultural $^{20}$ sempre se faz em um jogo de disputas, seja pela comunidade ou pelo poder público, mas que tem como base uma construção de uma tradição. Dentro desta concepção, pode-se utilizar o termo "tradição inventada", conforme apresentado por Eric Hobsbawm, entendo como "um conjunto de práticas, normalmente

\footnotetext{
18 “A contaminação microbiológica de moluscos é de origem antrópica, exceto as ligadas aos víbrios e bactérias marinhas introduzidas no meio pela transferência de moluscos cultivados em áreas epidêmicas" (WOLFF, 2007, p.166).

${ }^{19}$ Disponível em: <http://www.pmf.sc.gov.br/sites/fenaostra/index.php?cms=fenaostra\&menu=1>. Acesso em 8 jun. 2015.

${ }^{20}$ A discussão sobre o patrimônio imaterial no Brasil ganhou espaço a partir da Constituição Federal de 1988, quando a preservação cultural recebeu um conceito mais abrangente de "bem cultural". O artigo 216 da Constituição diz que: "Constituem patrimônio cultural brasileiro os bens de natureza material e imaterial, tomados individualmente ou em conjunto, portadores de referência à identidade, à ação e à memória dos diferentes grupos formadores da sociedade brasileira."
} 
reguladas por regras tácita ou abertamente aceitas; [onde] tais práticas, de natureza ritual ou simbólica, visam inculcar certos valores e normas de comportamento através da repetição, o que implica, automaticamente, uma continuidade em relação ao passado" (HOBSBAWM, 1997, p.9). Hobsbawm assim diferencia "tradição" e "costume", enquanto a "tradição" tem a característica e objetivo de ser invariável, impondo práticas fixas do passado através da repetição, por outro lado o "costume" não impede as inovações e permite mudanças, por entender que nem mesmo as sociedades tradicionais são tão invariáveis.

\subsection{Novos rumos para a cidade}

A cidade de Florianópolis segue em transformação de seu espaço urbano, implicando mudanças físicas e sociais desde o momento em que ocorre o afastamento do mar do Centro e expande os balneários turísticos para as áreas pesqueiras. Com isso, novos usos passam a ser feitos do mar, novos significados e novas sociabilidades surgem neste novo cenário. Ao compreender a cidade em sua dinâmica urbana e percebendo o cotidiano nas suas entrelinhas, permite-se identificar reinvenções e representações, muitas vezes próximas de outras tantas cidades.

Diante das transformações do século $\mathrm{XX}$, o mar foi ressignificado em seus usos ao receber novas dimensões e apropriações até ser considerado espaço de lazer e veraneio. Entre o desenvolvimento da maricultura e da cidade lazer, projeta-se um lugar relacionado com o mar de diferentes formas, colocando-se como um desafio de interpretação, sendo necessário perceber a cidade em suas pluralidades e singularidades através da interdisciplinaridade. Compreendendo que certos assuntos e objetos necessitam de colaboração entre diferentes disciplinas, a interdisciplinaridade permite uma visão crítica ao questionar os valores, aspectos sociológicos e educativos, dentro da perspectiva apresentada por Héctor Leis em que "a prática da interdisciplinaridade supõe o equilíbrio de dois aspectos, por um lado, uma visão integradora de diversas disciplinas e, por outro, um salto cognitivo que não esteja pressuposto em qualquer somatória de abordagens disciplinares" (LEIS, 2011, p.110). Sendo assim, este estudo amplia-se a cada novo olhar e busca contribuir com os estudos ambientais das zonas costeiras brasileiras. 


\section{Referências}

BECKER, Daniella de Sousa Maria. Diagnóstico da produção de moluscos no município de Florianópolis/SC. 2008. 121 f. TCC (Graduação) - Curso de Ciências Econômicas, Universidade Federal de Santa Catarina (UFSC), Florianópolis/SC, 2008.

BIDOU-ZACHARIASEN, Catherine. Introdução. In: BIDOU-ZACHARIASEN, Catherine (Coord.). De volta à cidade: Dos processos de gentrificação às políticas de "revitalização" dos centros urbanos. São Paulo : Annablume, 2006. p. 21-57.

CABRAL, Oswaldo. Nossa Senhora do Desterro: Notícia I. Florianópolis: UFSC, 1971.

CECCA, Centro de Estudos Cultura e Cidadania. Uma cidade numa ilha: relatório sobre os problemas sócioambientais da Ilha de Santa Catarina. Florianópolis : Insular, 1996.

FERREIRA, Sérgio Luiz. O banho de mar na Ilha de Santa Catarina. Florianópolis : Ed. das Águas, 1998.

HOBSBAWM, Eric. A invenção das tradições. Rio de Janeiro: Paz e Terra, 1997.

HUYSSEN, Andreas. Seduzidos pela memória. Rio de Janeiro : Aeroplano, 2000.

JEUDY, Henri Pierre. Espelho das cidades. Rio de Janeiro : Casa da Palavra, 2005.

LEIS, Héctor Ricardo. Especificidades e desafios da interdisciplinaridade nas ciências humanas. In: PHILIPPI Jr, Arlindo e SILVA NETO, Antonio. Interdisciplinaridade em Ciência, Tecnologia e Inovação. Barueri, SP : Editora Manole, 2011. p. 106-122.

PROCHNOW, Ronan Max; DAL SANTO, Mariane Alves; AMEY, Robert. A expansão das cidades sobre a Zona Costeira: Estudo de Caso de Florianópolis, BR, e Boston, USA. EGAL-Encontro de Geógrafos da América Latina, 2009.

SÁNCHEZ, Fernanda. A reinvenção das cidades na virada de século. Revista de Sociologia e Política, Jun. 2001, no 16, p. 31-49.

SANTA CATARINA. Síntese Informativa da Maricultura 2013. Florianópolis : Empresa de Pesquisa Agropecuária e Extensão Rural de Santa Catarina - Epagri, Secretaria de Estado da Agricultura e da Pesca, 2013.

SMITH, Neil. A gentrificação generalizada: de uma anomalia local à uma "regeneração" urbana como estratégia urbana global. In: BIDOU-ZACHARIASEN, Catherine (Coord). De volta à cidade: Dos processos de gentrificação às políticas de "revitalização" dos centros urbanos. São Paulo : Annablume, 2006. p.59-87.

SUGAI, Maria Ines. As intervenções viárias e as transformações do espaço urbano. A via de contorno norte-Ilha. 2v. Dissertação (Mestrado em Arquitetura) - Faculdade de Arquitetura e Urbanismo, Universidade de São Paulo, 1994.

VÁRZEA, Virgílio. Santa Catarina: a Ilha. Florianópolis : Ed. Lunardelli, 1985.

VILLAÇA, Flávio. Espaço intra-urbano no Brasil. Studio nobel, 1998.

WOLFF, Ruy Ávila. Avaliação de parâmetros oceanográficos em áreas de produção de ostras nas águas da baía Sul (SC) - Brasil. 2007. 244 f. Tese (Doutorado) - Curso de Programa de Pós-graduação em Geografia, Centro de Filosofia e Ciências Humanas, Universidade Federal de Santa Catarina, Florianópolis, 2007. Disponível em: <https://repositorio.ufsc.br/handle/123456789/103181>. Acesso em: 23 out. 2015. 